\title{
Effects of light polarization and crystal orientation on the holographic recording efficiency in doped $\mathrm{LiNbO}_{3}$ crystals
}

\author{
$\underline{\text { A.Ozols }}{ }^{1}$, M.Reinfelde ${ }^{2}$ \\ ${ }^{1}$ Institute of Technical Physics, Riga Technical University, 14/24 Azenes Str., LV-1048, \\ Riga, Latvia \\ ${ }^{2}$ Institute of Solid State Physics, University of Latvia, 8 Kengaraga Str., LV-1063, Riga, \\ Latvia
}

Holographic grating recording by $\mathrm{He}-\mathrm{Ne}$ laser $(633 \mathrm{~nm})$ in $\mathrm{LiNbO}_{3}: \mathrm{Fe}, \mathrm{LiNbO}_{3}: \mathrm{Cu}$, $\mathrm{LiNbO}_{3}: \mathrm{Fe}+\mathrm{Cu}, \mathrm{LiNbO}_{3}: \mathrm{Fe}+\mathrm{Ti}$ crystals has been experimentally studied depending on their oxidation degree, on the recording and readout light polarization as well as on the crystal orientation $\left(\boldsymbol{K} \| \boldsymbol{P}_{s}\right.$ or $\boldsymbol{K} \perp \boldsymbol{P}_{s}, \quad \boldsymbol{K}$ being the holographic grating vector, $\boldsymbol{P}_{s}-$ spontaneous polarization). The crystals were kept about 20 years at room temperature before the first recording. Each next recording was performed after the annealing of crystal at $200^{\circ} \mathrm{C}$.

Annealing considerably improved the diffraction efficiency $\eta$ and the specific recording energy $W$ in all cases except $\mathrm{LiNbO}_{3}: \mathrm{Fe}$ at $\boldsymbol{K} \perp \boldsymbol{P}_{\boldsymbol{s}}$ case. The $\boldsymbol{K} \| \boldsymbol{P}_{\boldsymbol{s}}$ orientation was much more efficient than $\boldsymbol{K} \perp \boldsymbol{P}_{\boldsymbol{s}}$ one. The best results were obtained for $\mathrm{LiNbO}_{3}: \mathrm{Cu}$ crystals $\left(\eta_{\text {oomax }}=40 \%, W_{\text {eomax }}=6.8 \mathrm{~J} /\left(\mathrm{cm}^{2} \%\right)\right.$; indices denote the recording and readout polarization $)$. Recording efficiency of crystals decreases in the following order: $\mathrm{LiNbO}_{3}: \mathrm{Cu}, \mathrm{LiNbO}_{3}: \mathrm{Fe}$, $\mathrm{LiNbO}_{3}: \mathrm{Fe}+\mathrm{Cu}, \mathrm{LiNbO}_{3}: \mathrm{Fe}+\mathrm{Ti}$. The recording efficiency polarization dependence of $\mathrm{LiNbO}_{3}: \mathrm{Cu}$ crystals markedly differed from the known polarization dependence of $\mathrm{LiNbO}_{3}: \mathrm{Fe}$ crystals. The obtained results can be explained regarding the influence of possible defects on the absorption and photogalvanic effect as well as electrooptic properties of crystals. 


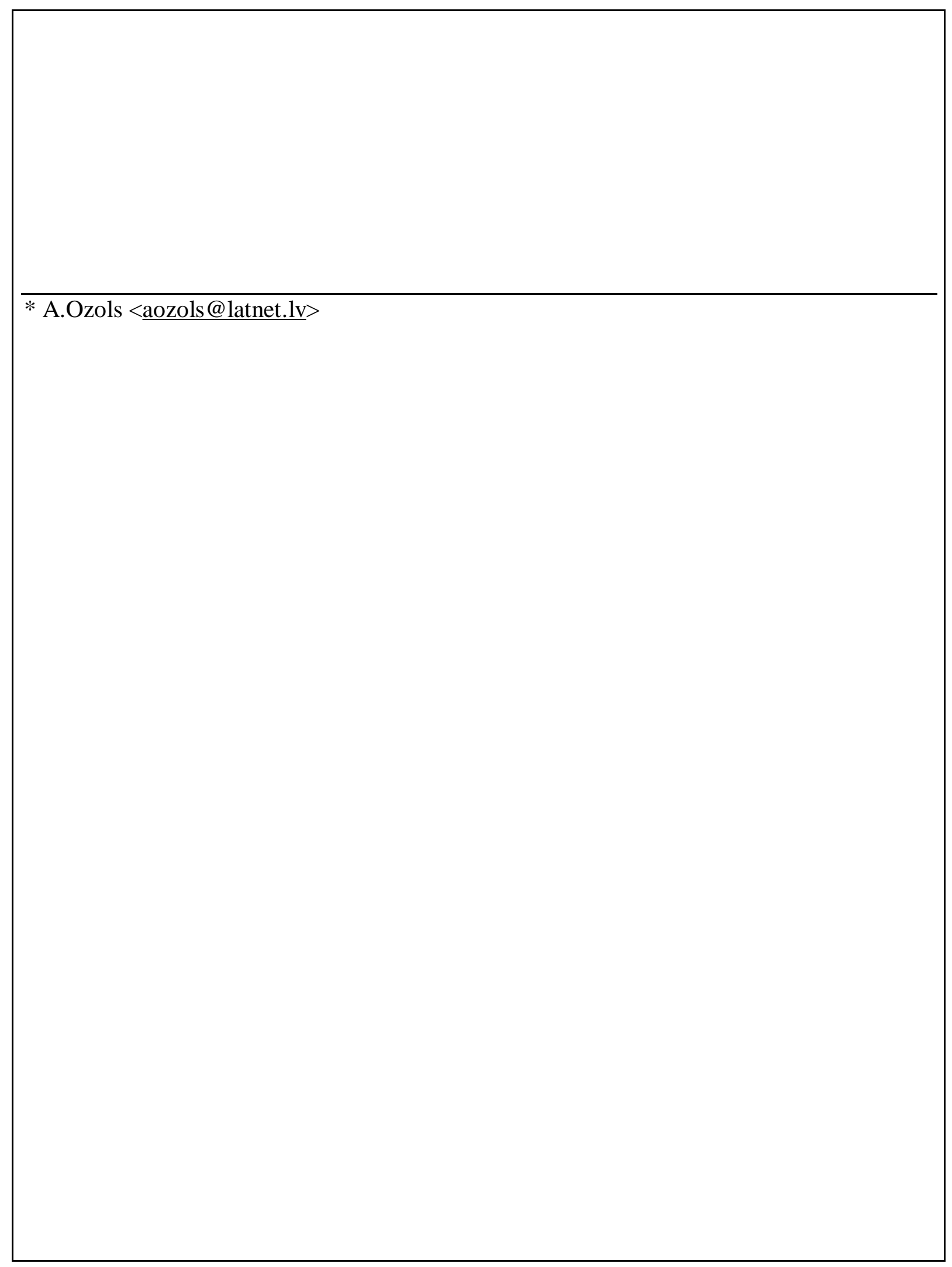

